\title{
An Electronic Intelligent Hotel Management System For International Marketplace
}

\author{
Md. Noor-A-Rahim ${ }^{1}$, Md. Kamal Hosain ${ }^{2}$, Md. Saiful Islam ${ }^{3}$, Md. Nashid Anjum ${ }^{4}$ and Md. Masud Rana ${ }^{5}$ \\ 1,3,4,5 Electronics \& Communications Engineering, Khulna University of Engineering and Technology (KUET), Khulna, \\ Bangladesh. \\ ${ }^{2}$ School of Engineering, Deakin University, Geelong, Victoria 3217, Australia. \\ E-mail: mash_0409@yahoo.com ${ }^{1}$, mhosain@deakin.edu.au ${ }^{2}$, sirajonece@yahoo.com ${ }^{3}$, nashidzone@yahoo.com ${ }^{4}$, and \\ mamaraece28@yahoo.com ${ }^{5}$
}

\begin{abstract}
To compete with the international market place, it is crucial for hotel industry to be able to continually improve its services for tourism. In order to construct an electronic marketplace (e-market), it is an inherent requirement to build a correct architecture with a proper approach of an intelligent systems embedded on it. This paper introduces a web based intelligent that helps in maintaining a hotel by reducing the immediate involvement of manpower. The hotel reception policy, room facilities and intelligent personalization promotion are the main focuses of this paper. An intelligent search for existing boarders as well as room availability is incorporated in the system. For each of the facilities, a flow chart has been developed which confirms the techniques and relevant devices used in the system. By studying several scenarios, the paper outlines a number of techniques for realization of the intelligent hotel management system. Special attention is paid to the security and also prevention of power and water wastages. In this power saving scenery, an image processing approach is taken to detect the presence of any people and the darkness in a particular room. Moreover, this proposed automated computerized scheme also takes an account of the cost advantage. Considering the scarcity of manpower in several countries, the objective of this paper is to initiate the discussion and research for making the proposed systems more commercialized.
\end{abstract}

Keywords- E-marketplac; hotel managemen; intelligent search; intelligent system; image processing algorithms; web-based application

\section{INTRODUCTION}

In order to triumph in the fierce competition of hotel service industry, the main goal and orientation of hotel management are how to provide customers high quality and humanized services. To compete with the international e-marketplace, a great deal of attention should pay towards the optimization of user requirements to generate recommended hotel alternatives [1]. In general sense, hotel management is the way of maintaining different activities of a hotel where a number of staffs are engaged to perform a number of these activities. At first let us take a glance to an ordinary hotel. For hiring a room in this type of hotel, the client needs to meet with the receptionist to collect the information of hotel facilities[2]. After that he is to fill up the pro forma provided by the hotel authority, then he has to pay the defined amount of money and is offered room key for his/her rented room. He/she is then finishes the formalities at reception zone through these undergoing customs. But client always wants greater privacy and reliable security. Koolmanojwong et al. [3] developed an intelligent e-marketplace for the tourism based on fuzzy to serve the customers who wants to travel but has no idea about the accommodation[4]. This system is global in the sense that anyone can use this to find the appropriate hotel according to his/her affordable means [5]. The details of the hotel management systems including the franchising, casinos, health Spas, payroll, credit, accounting control etc. are well described in [6]. However, we have designed an IHM system which is specific to a particular hotel. It helps the owner to serve the intended customers without directly involving with them. This system has included the electronic circuitry embedded with several sensors in integrated with the java programming.

The proposed intelligent hotel management (IHM) system is free from a significant number of hotel staffs that provides those facilities and fewer formalities. In mal-populated countries dearth of manpower is increasing gradually. Therefore, they have to import manpower from other countries. In this condition the IHM can be a permanent solution. Moreover, it possesses adequate security [7]. This system provides hi-tech room facilities including auto controlled door, automatic light controlling, voice active devices etc. Apart from these, it prevents the waste of electric power as well as excessive water that are the main ideas used in this paper. A short version of this approach is in [8]. Additionally, we have integrated a new image processing approach which accurately ensures the presence and darkness of the room to be occupied.

\section{PROPOSED INTELLIGENT Hotel MANAGEMENT SYSTEM}

Generally, the information provided in conducting an international electronic marketplace (E-marketplace) for hotel management is not enough. The intelligent functions as a helping hand to the new visitors in such a place a great integration and initiative is offered[9]. In an ordinary hotel management system there must be a receptionist to interact with customers. Since IHM involves a fewer number of hotel staff, there should be a way in reception zone to distinguish between a client (who wants to rent a room for accommodation) and a guest (who wants to visit a border in a hotel). Some indispensable activities such as pro forma filling, 
bill payment, getting the room key should be accomplished in reception zone. To provide the substantial information about the competences of the hotel, a virtual hotel guide is an urgent need. The general system function of an intelligent hotel management is shown in Fig. 1 which includes a reception zone and intelligent architecture. We have proposed an intelligent management of a modern hotel where all the facilities and services to the customers have been maintained in an efficient way.

The following Fig. 2 furnishes an overview about this proposed IHM architecture. It depicts that the reception zone is operated by the central controlling unit; room devices and other activities of rooms are operated by local controlling unit. Each local controlling unit is connected with central controlling unit. For overall security there is a security zone. It monitors the whole system including reception zone, hotel corridor and other pertinent areas from any unpleasant incidents. The following section provides a possible way to establish such type of system. This proposed system includes a reception procedure, room facilities, and border searching. In addition, we have implemented an image processing algorithm which ensures the prevention power wastage. This whole system was implemented in our lab (Fig. 3) which worked perfectly.

\section{A. Intelligent reception procedure for hotel accommodation}

When a client attends to the reception booth the infra sensor gets activated. A display is then appeared on the monitor/electronic screen containing three options: i) hotel information, ii) new entry, and iii) border searching. If the new entry option is selected a pro forma is appeared on the screen.
It contains information fields about the client e.g., client's name, address, and other information. It also contains the room category and rent duration fields [10], [11]. The first selection shows the available room categories and the later one ensures the number of days for which the room is rented. After submitting the pro forma accurately, the display screen will show the amount of payment of the particular room. After completing these schedules, when the client leaves the booth the infra sensor becomes deactivated automatically and the screen resumes to the initial state[12]. This step by step information shows in the following Fig. 4 in details.

\section{B. Intelligent management of room facilities}

When the border comes in front of his rented room then another infra sensor is activated and the border is instructed automatically to type his/her room password. The door of the room will be opened automatically if the typed password matches with the password which is created and confirmed at the reception booth. If the room is empty then an intelligent image processing method runs as soon as the door is opened. This method measures the darkness of this room [13], [14]. This process takes an image of the room as soon as the door opens. The image is then processed by which the darkness of the room is compared. If the room is not enough lighted then the electric appliances are turned on automatically. The entire process is followed by the following flow chart (Fig. 5).

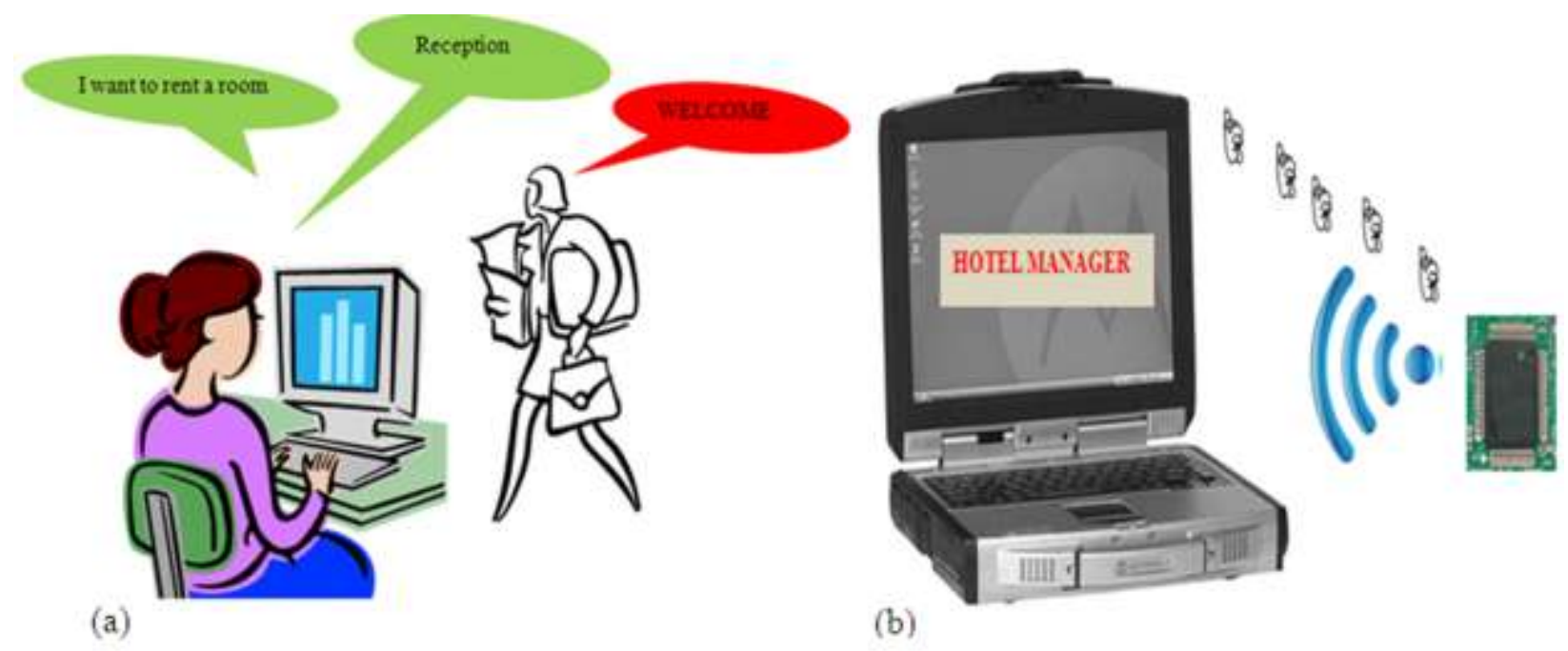

Figure 1. System function of an automated hotel, (a) Register in reception, (b) Information sending. 


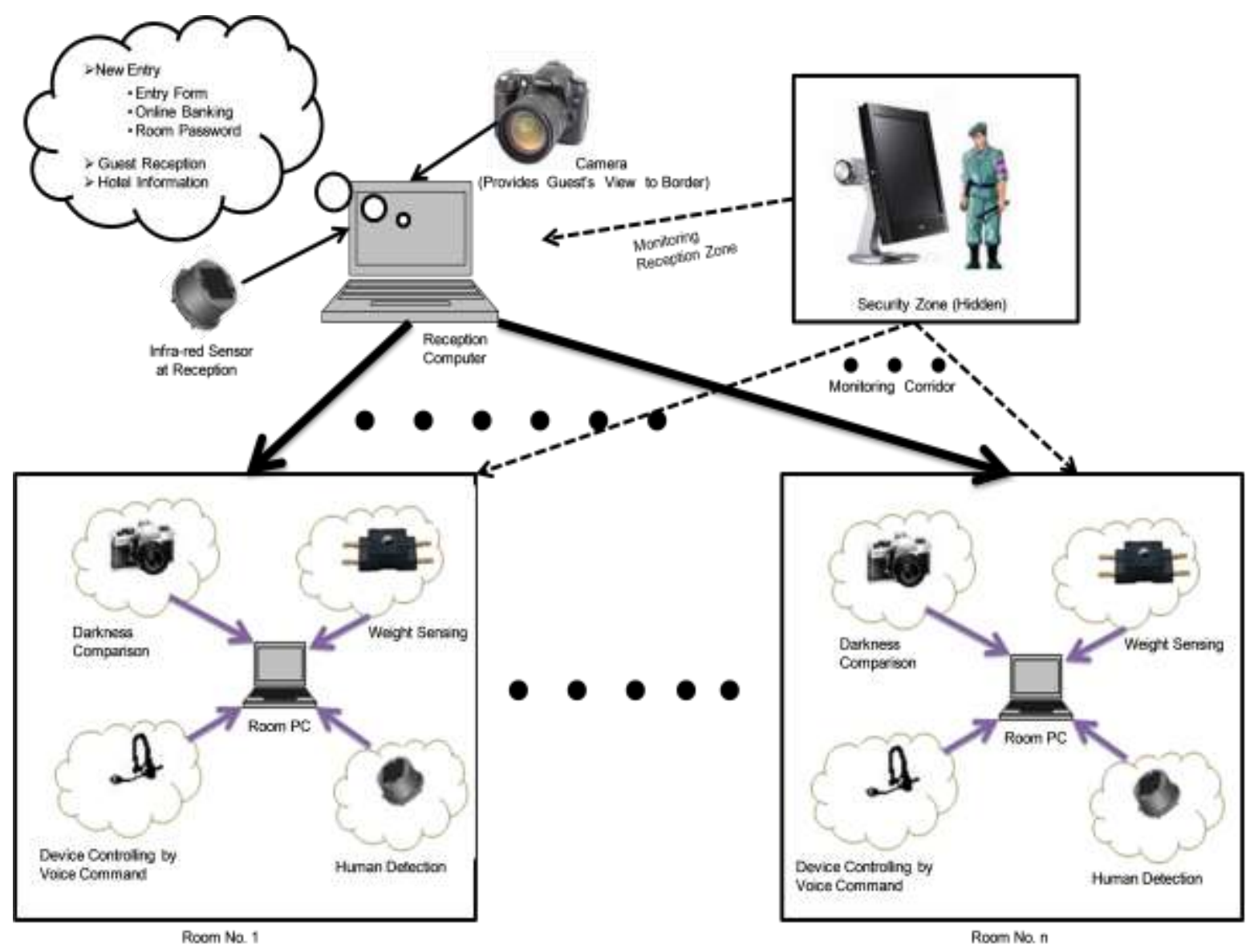

Figure 2. Block diagram illustrating the proposed intelligent hotel management system.

1) Image processing scheme: In this hi-tech room facilities, an intelligent image processing has been integrated which ensures the presence and darkness of the intended room. A web camera is set in a suitable location inside the room which can capture snap of the significant portion of the room including the area where usually the person stays. We have used the built-in function of java script which extracts the RGB value from the captured image[15], [16], [17]. This program is written and integrated with the system specifically for this design. The process of monitoring the room's light is explained in Fig. 6.

2) Controlling devices through voice command scheme: In an ordinary hotel, clients used to operate the electronic devices manually. But automatic control is more suitable and easier than manual control. This proposed IHM system provides the benefits to control the electronic equipments such as: light, fan or air-condition, TV etc. using voice command. For example, to turn on the light simply 'light on' command is enough. This is done by following process as shown in Fig. 7. Besides these facilities, this proposed method includes manual control system as well[18], [19].

3) Prevention of wastage: IHM is well concerned about wastage prevention. To prevent wastage of water it uses infra sensor which is used to auto turn on and turn off the faucet. It is done by following way as shown in Fig. 8. On the other hand
IHM also prevents the electric power. When the room becomes empty the lights, fans and other electronics devices are automatically turned off.

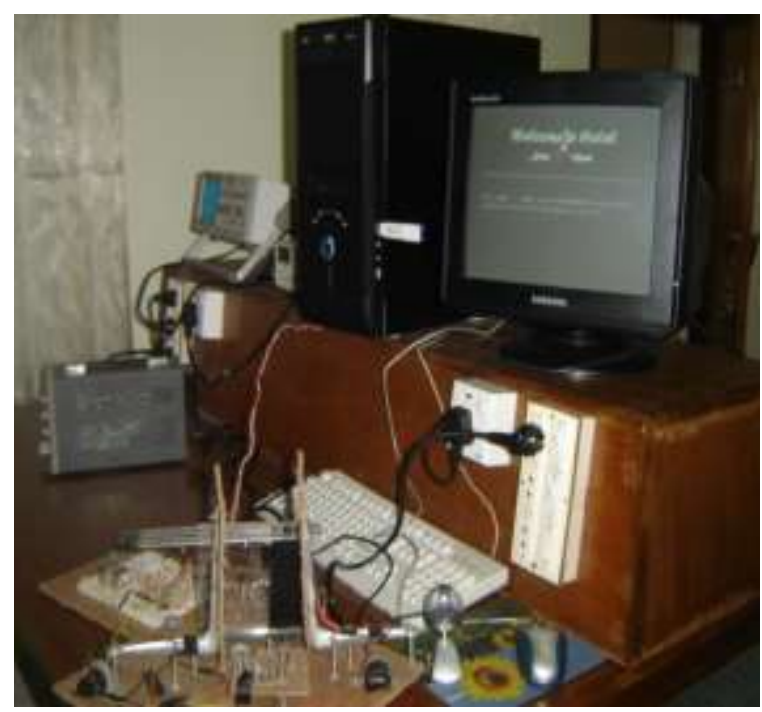

Figure 3. Basic arrangement and test of the proposed IHM system. 


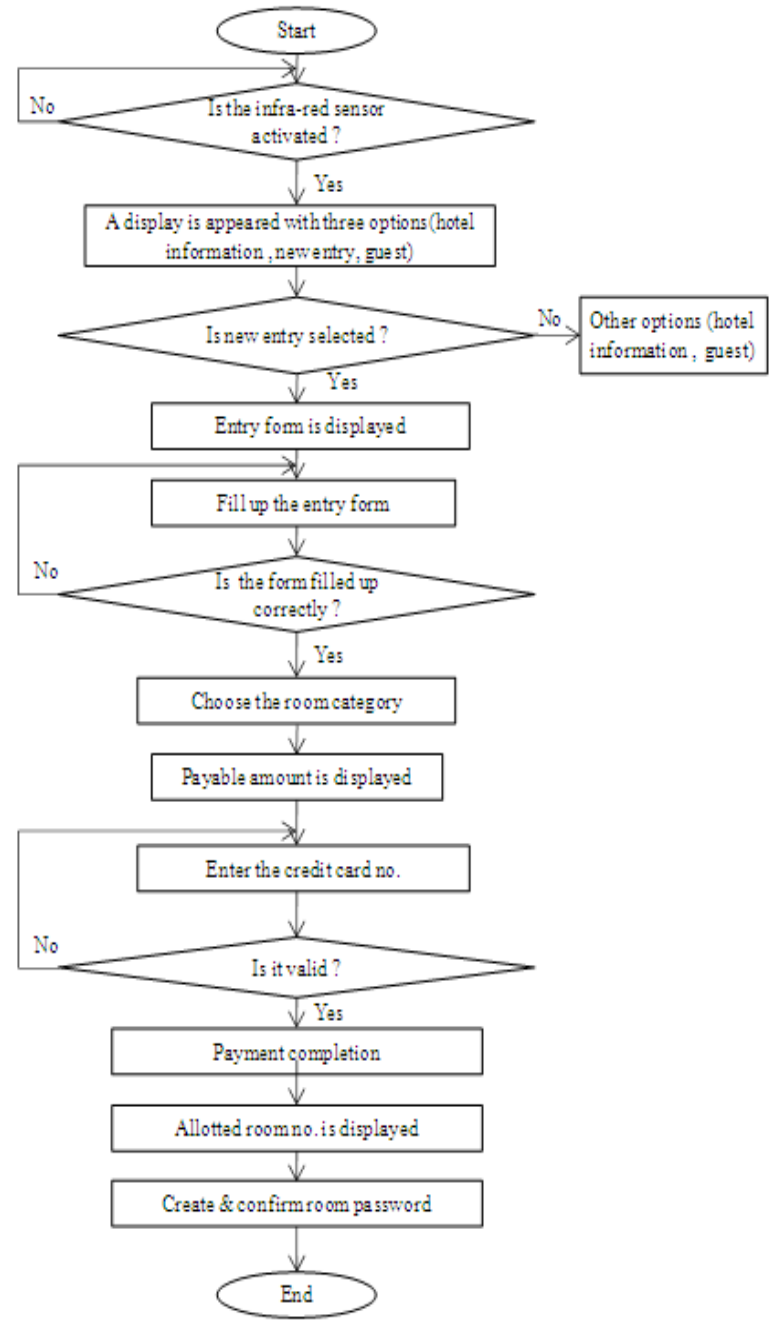

Figure 4. Flow chart of entry of a customer in a proposed hotel system.

\section{INTELLIGENT SEARCHING OF A BORDER}

While staying in a hotel, it is important to maintain the privacy and of course with high security. Before, allowing the guest to meet with the border the border must have a chance to see him so he/ she might have the right whether allowed or not the guest. Figure 9 illustrates this interaction between the border and the guest who comes to the hotel to meet a desired border.

When the guest comes to the reception booth, again the infra sensor will be activated and the electronic screen will display three options as described in previously. Now the guest will select the border searching option (also termed as Guest option). Then there will appear a form, the purpose of which is to take the guest's name and address. It also contains two preferences to take desired border's name and room number. If the desired border is not available then a message will be displayed on the screen to inform that news [13]. But if the desired border is available then a confirmation message will be sent to the border to inform him that he has a guest. And a display with three options will be appeared on the screen which is placed in the border's room. Using first option the border will be able to verify the identity of the guest by watching him live on the screen of his own room. Using the second and third option he will be able to allow or deny the guest. If the border allows the guest then the system will generate a random password which can be [20] used for only one time and within a fixed period of time. If the border denies the guest then the guest will receive a message which informs that the border is not available.

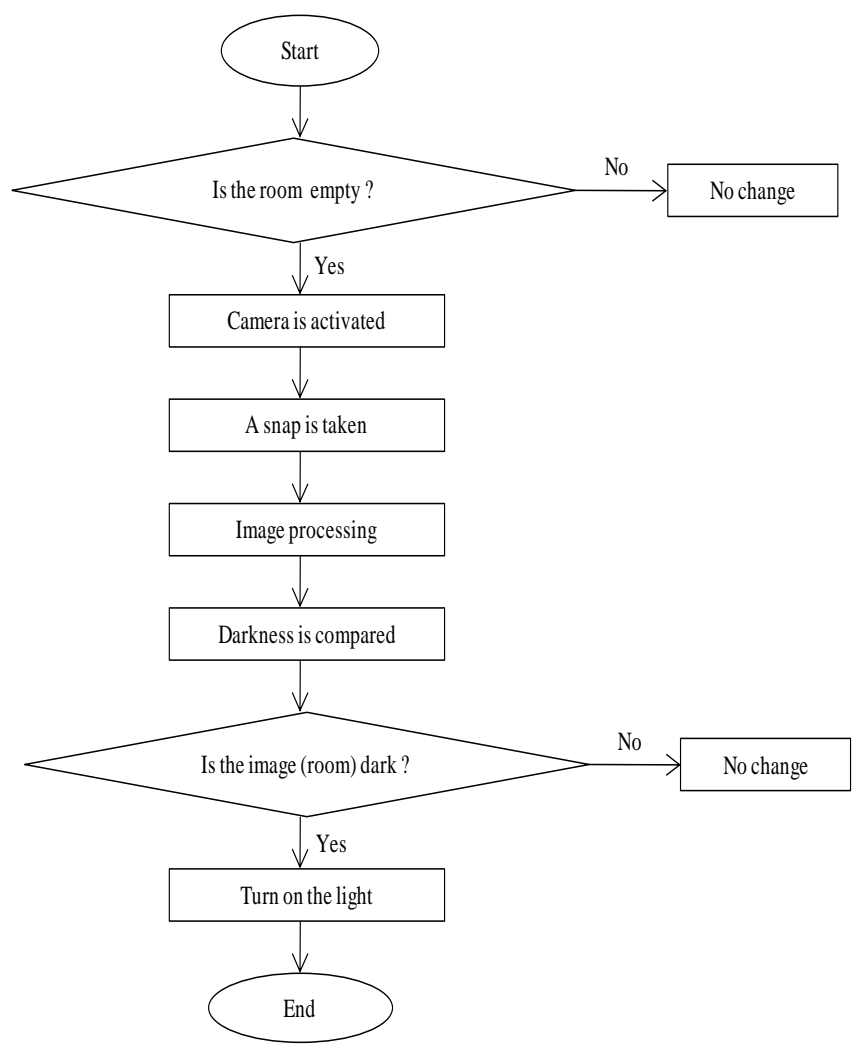

Figure 5. Flow chart of the to maintain the automatic turn on the light (when the border enters in an empty room.

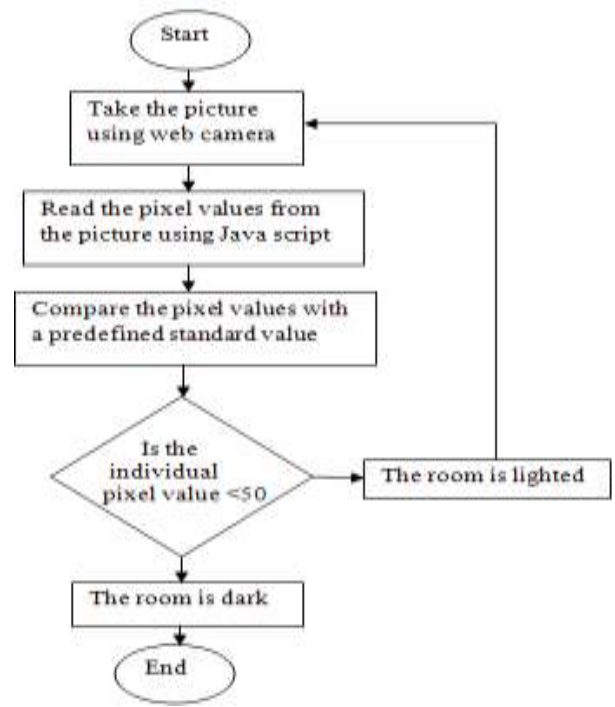

Figure 6. Flow chart of to show process of monitoring the room's condition. 


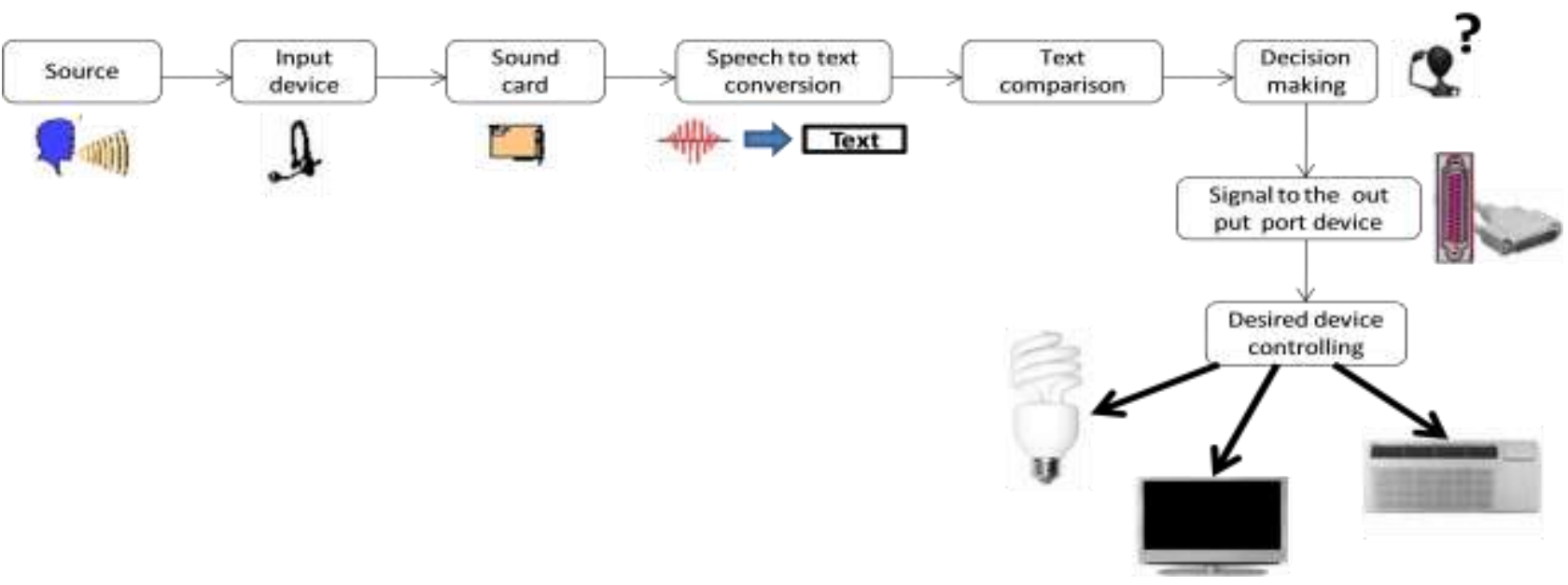

Figure 7. Block diagram of controlling devices by voice command.

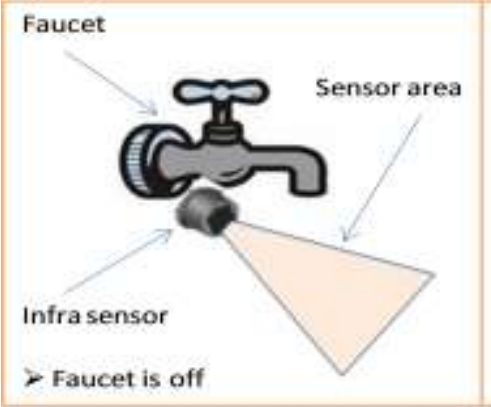

Step : 1

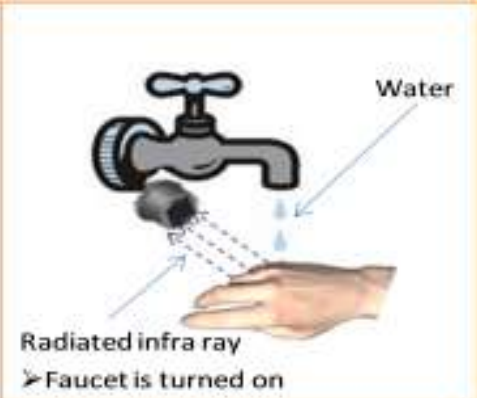

Step : 2

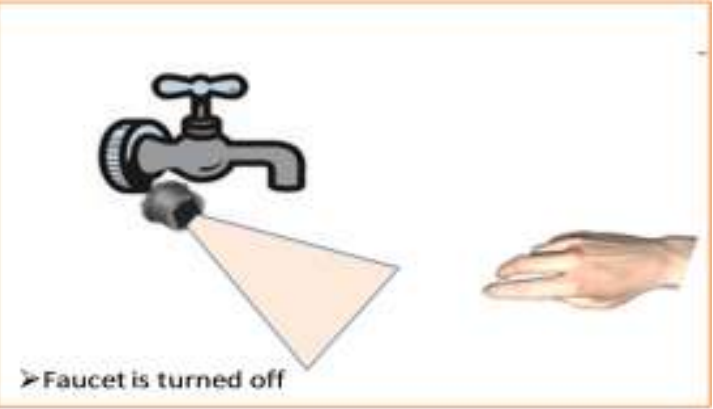

Step : 3

Figure 8. An approach of infra sensor for the controlling of water to be utilized.

\section{FUTURE WORKS AND MOTIVATIONS}

In order to meet the full customer requirements and to compete with the international marketplace the proposed IHM should incorporate the following facilities: intelligent room condition indicator, intelligent id recognizer, room condition indicator, system self-checking, the announcement of information, air-conditioner controller[21]. We are now considering the above approaches to be incorporated with the IHM system.

\section{CONCLUSION}

In this era of high technology, everything is attaining more and more automation dependent. Hotel management system also should be involved in the realm of automation. This proposed intelligent management system provides high level privacy than the existing conventional manual system with greater reliability. To satisfy the customer's need, this project work provides a seamless and enjoyable experience for customers.
Introducing this automotive management system in any kind of accommodation systems greatly reduced manpower and maintenance cost. In addition, the incorporation of infrared detection systems and the image processing scheme in the respective rooms helps to the prevention of power and water wastages. Moreover, the web based system increases the security and privacy by employing a web camera which ensures the live pictures of any occurrence happened in the hotel. This is our own concept and has been already successfully implemented as a project work in miniature version. In fact, this system is fast, comprehensive and flexible, but doesn't necessarily require ones to have that much skill in computer science. 


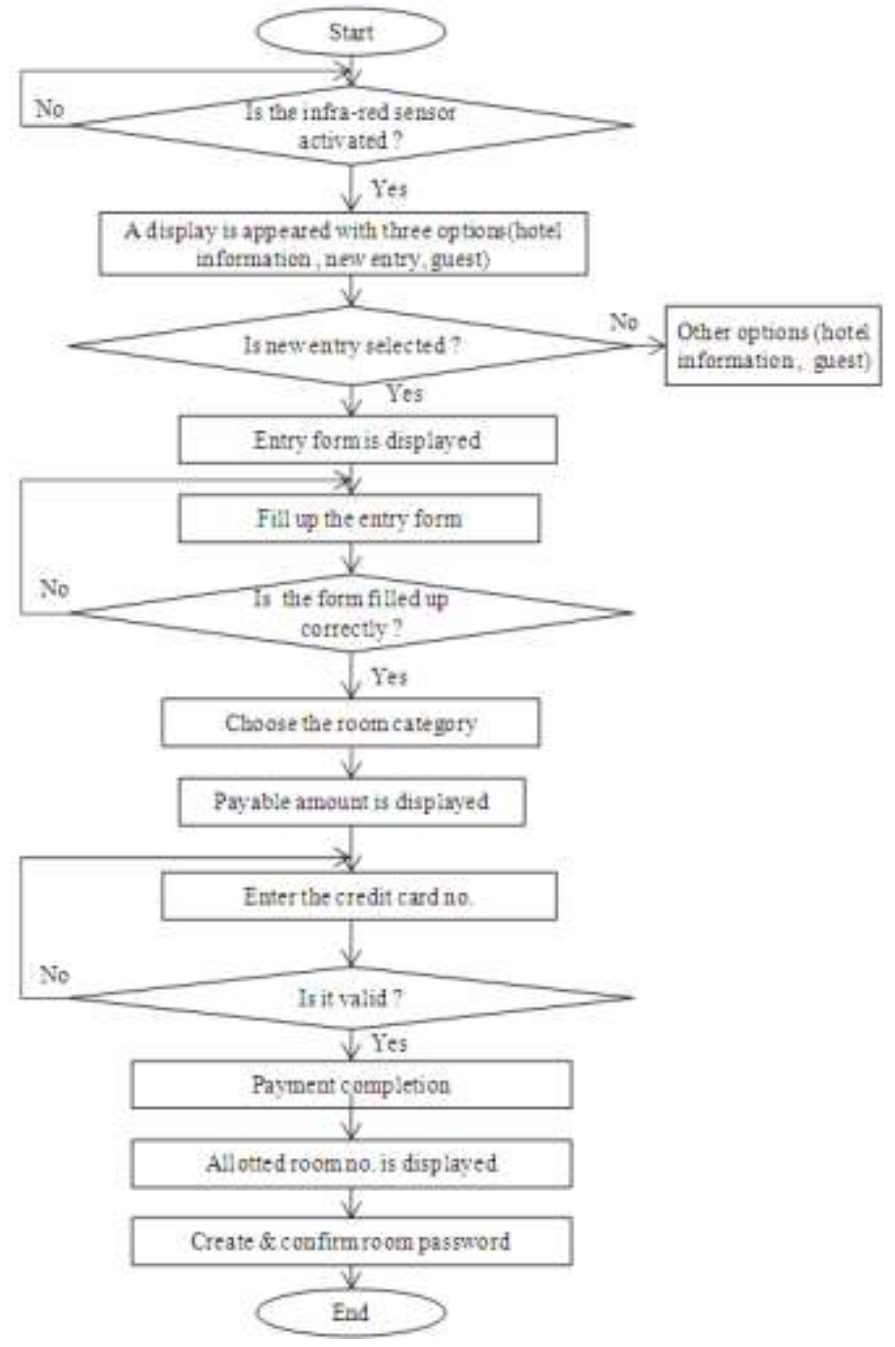

Figure 9. Flow chart to show the entry procedure of a customer in the proposed IHM.

\section{REFERENCES}

[1] S. Koolmanojwong, "Analysis and Design of B to C EMarketplace for Tourism with UML " M.S. Thesis, Faculty of Science and Technology, Assumption University, Bangkok, Thailand 2000.

[2] M. J. O'Fallon and D. G. Rutherford. (2011). Hotel Management and Operations | CA College of Ayurveda. Available: http://www.ayurvedacollege.com/amazon_store/item/0470177144

[3] S. Koolmanojwong and P. Santiprabhob, "Intelligent Electronic Marketplace for Tourism."

[4] E. W. T. Ngai and F. K. T. Wat, "Design and development of a fuzzy expert system for hotel selection," Omega, vol. 31, pp. 275286, 2003.

[5] G. Jingzhi, et al., "Alibaba International: Building a Global
Electronic Marketplace," in e-Business Engineering, 2006. ICEBE '06. IEEE International Conference on, 2006, pp. 545-548.

[6] W. S. Gray and S. C. Liguori, Hotel and Motel Management and Operations, Fourth Edition ed.: Prentice Hall, 2002.

[7] W. J. Relihan Iii, "The yield-management approach to hotel-room pricing," The Cornell Hotel and Restaurant Administration Quarterly, vol. 30, pp. 40-45, 1989.

[8] M. S. Islam, et al., "An Automated Intelligent Hotel Management System," in 2009 Interdisciplinary Conference in Chemical, Mechanical and Materials Engineering (2009 ICCMME), Melbourne, Australia, 2009.

[9] J. Guo, et al., "CONFENIS Special Session on the International Symposium on Electronic Marketplace Integration \&amp; Interoperability (EM2I'07)," in Research and Practical Issues of Enterprise Information Systems II. vol. 255, L. Xu, et al., Eds., ed: Springer Boston, 2008, pp. 823-823.

[10] K. Riemer and C. Lehrke, "Biased Listing in Electronic Marketplaces: Exploring Its Implications in On-Line Hotel Distribution," Int. J. Electron. Commerce, vol. 14, pp. 55-78, 2009.

[11] Y.-n. Xiong and L.-x. Geng, "Personalized Intelligent Hotel Recommendation System for Online Reservation--A Perspective of Product and User Characteristics," in Management and Service Science (MASS), 2010 International Conference on, 2010, pp. 1-5.

[12] J. A. Bardi. (2011). Wiley::Hotel Front Office Management 5th Edition. Available: http://eu.wiley.com/WileyCDA/WileyTitle/productCdEHEP001784.html?filter=TEXTBOOK

[13] Y. Ming-Ju, et al., "Multicast Services of Digital Television in a New Management Framework," in Intelligent Information Technology Application Workshops, 2008. IITAW '08. International Symposium on, 2008, pp. 296-299.

[14] M. Ben Ghalia and P. P. Wang, "Intelligent system to support judgmental business forecasting: the case of estimating hotel room demand," Fuzzy Systems, IEEE Transactions on, vol. 8, pp. 380$397,2000$.

[15] R. Jiamthapthaksin, "Fuzzy information retrieval with respect to graded features," Masters Thesis, Assumption University, 2000.

[16] M. Wojcikowski, et al., "An intelligent image processing sensor the algorithm and the hardware implementation," in Information Technology, 2008. IT 2008. 1st International Conference on, 2008, pp. 1-4.

[17] "Session 11: intelligent image processing," in Computational Intelligence for Measurement Systems and Applications, 2005. CIMSA. 2005 IEEE International Conference on, 2005, pp. 186186.

[18] D. B. Roe and Y. Wang, "A voice-controlled network for universal control of devices in the OR," Minimally Invasive Therapy \& Allied Technologies: MITAT: Official Journal Of The Society For Minimally Invasive Therapy, vol. 9, pp. 185-191, 2000.

[19] H. G. Nik, et al., "Voice Recognition Algorithm for Portable Assistive Devices," in Sensors, 2007 IEEE, 2007, pp. 997-1000.

[20] "Hotel Yield Management Practices Across Multiple Electronic Distribution Channels," Information Technology \&\#38; Tourism, vol. 10, pp. 161-172, 2008.

[21] Available: http://www.smarthomeuae.com/productfile/0000000000427a.pdf 